\title{
El Performance de los Docentes en la Idea de Justicia: Elementos para una Crítica de la Doctrina Moral en su Trabajo
}

\author{
The Performance of Teachers in the Idea of Justice:Elements \\ for a Criticism of Moral Doctrine in their Work
}

\section{O Desempenho dos Docentes na Ideia de Justiça: Elementos para uma Crítica da Doutrina Moral em seu Trabalho}

\author{
Miguel Ángel Olivo Pérez * \\ Universidad Pedagógica Nacional
}

\begin{abstract}
El presente artículo recupera la idea de justicia de Alain Badiou, con el propósito de contribuir a enunciar algunos términos que permitan identificar y combatir la moral doctrinaria subyacente al performance del trabajo de los docentes de educación básica. Se trabajan conceptos provenientes de la sociología del trabajo, el psicoanálisis lacaniano y la filosofía posfundacional, mismos que reflexionados a la luz del excesivo énfasis en la disciplina y la burocracia en la educación básica, sirvieron para sostener el argumento de que aplicar la idea de justicia de Alain Badiou en el ámbito de la educación escolarizada, exige: a) combatir el prejuicio de que los programas y las reglamentaciones elaboradas por expertos redundan en una mejora automática, b) defender la idea de justicia como acción fiel y disciplinada en torno a la igualdad y dignidad de los cuerpos con ideas. Se propone el trabajo de los docentes, como la primera instancia a partir de la cual debería de comenzar su formación en la idea de la justicia de la igualdad de los cuerpos con ideas. Como contribución central, se elabora el término de cuasipolítica, entendida como el acto de enunciar el atravesamiento de la imposibilidad de desaparecer la división del trabajo entre expertos y simples ejecutores.
\end{abstract}

Descriptores: Justicia, Educación básica, Ética, Moral doctrinaría, Cuasipolítica.

The present article retrieves the idea of justice of Alain Badiou, with the aim of contributing to enunciate some terms that will identify and combat the doctrinal morality underlying the work performance of basic education teachers. Concepts from Labour Sociology, Lacanian psychoanalysis and Post-foundational philosophy are worked, in order to reflect the light in reference to the overemphasis in discipline and bureaucracy in basic education. They also served to sustain the argument that applied the idea of Alain Badiou's justice on the field of formal school education which requires: a) to fight against the prejudice that programs and regulations drawn up by experts, automatically result in an improvement, b) to defend the idea of justice as a faithful and disciplined action around the equality and dignity of bodies with ideas. The work of teachers is proposed as the first instance from which they should start their training in the idea of justice for equality between bodies with ideas. As a central contribution, the term of quasipolitical is understood as the act of state, in the inability of crossing the disappearing division of labour between experts and simple executors.

*Contacto: miguelangelolivo@hotmail.com

ISSN: 2254-3139

www.rinace.net/riejs/

revistas.uam.es/riejs
Recibido:

16 de septiembre 2016

$1^{\text {a }}$ Evaluación: 15 de octubre 2016

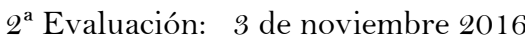

Aceptado: $\quad 8$ de noviembre 2016 
Keywords: Justice, Basic education, Ethics, Moral doctrine, Quasipolitical.

O presente artigo recupera a ideia de justiça social de Alain Badiou, com o propósito de contribuir na enunciação de alguns términos que permitem identificar e lutar pela moral doutrinária subjacente ao desempenho do trabalho dos docentes da Educação Básica. Em consequência, para cumprir com a referida tarefa, foram trabalhados conceitos provenientes da sociologia do trabalho, a psicoanálise lacaniano e a filosofia posfundacional, que refletidos a luz da excessiva ênfase na disciplina e a burocracia na educação básica, serviram para sustentar o argumento de que aplicar a ideia de justiça de Alain Badiou no âmbito da educação escolarizada exige: a) combater o preconceito de que os programas e os regulamentos desenvolvidos por especialistas resultarão automaticamente em uma melhoria do ensino-aprendizagem da educação em geral, b) defender a ideia de justiça como ação fiel e disciplinada em torno à igualdade e dignidade dos corpos com ideias. $\mathrm{O}$ trabalho dos docentes é proposto como a primeira instância a partir da qual deveria começar sua formação na ideia de justiça de igualdade dos corpos com ideias, o qual por sua vez implica questionar o contexto político e econômico no qual se desenvolve a educação em conjunto. Como contribuição central, se elabora o término de quase-política, entendido como o ato de enunciar o atravessamento da impossibilidade de desaparecer a divisão do trabalho entre especialista e simples executores.

Palavras-chave: Justiça, Educação básica, Ética, Moral doutrinária, Quase-política.

\section{Introducción}

Actualmente en diversos países existe un generalizado consenso de que el excesivo énfasis en la disciplinización y burocratización de la enseñanza repercute en un significativo detrimento de la educación. Así, refiriéndose al caso de Alemania de los años sesenta, Theodor Adorno señala la antipatía generada por la "excesiva reglamentación impuesta por los planes de enseñanza [ ...] propios de la escuela regimentada" (Adorno, 2003, p. 64). Por su parte, en el contexto de discusión europea sobre el discurso emancipador de la educación, Eduardo Terrén asevera que el discurso disciplinario que acompañó al ideal educativo "amparó la más férrea realización de su vertiente sistematizadora” (Terrén, 1999, p. 59). Michael Apple menciona abiertamente el carácter internacional de la problemática cuando reconoce que "en demasiados casos la vida cotidiana de los profesores en las aulas de muchas naciones está cada vez más controlada, más sometida aún a la lógica administrativa que trata de llevar la rienda de los procesos de enseñanza y del currículum” (Apple, 2003, p. 12).

No obstante los perjuicios que el régimen de control basado en la disciplina y la burocratización conllevan para la educación, los docentes han incorporado en el performance de su trabajo cotidiano la premisa central que sostiene la moral doctrinaria: la división del trabajo entre expertos y simple ejecutores mecánicos. Tal divisoria fundamental permea la idea de justicia en cualquier ámbito del trabajo de los docentes. Hay dos formas de concebir la idea de justicia en el trabajo del docente: como una idealidad doctrinaria impuesta por expertos desde el exterior a su trabajo y como diversas formas interiores de dilucidar in situ la justicia de la igualdad de los cuerpos con ideas propias. Así, el presente artículo propone el trabajo como el primer lugar a partir del cual se debe comenzar a formar a los docentes en la idea de justicia como igualdad de cuerpos con ideas.

El término performance, proveniente de la antropología, fue introducido extensivamente por Peter McLaren (1995) en el campo de la educación a través de su conocido estudio 
"La escuela como un performance ritual”. El antropólogo Víctor Turner (1987) recurre al concepto de performance para analizar dramas sociales acontecidos en escenarios en los que, si bien las acciones transcurren a través del seguimiento de reglas preestablecidas, existe siempre un margen para su manipulación, apertura y alteración. Analizar el trabajo docente desde el punto de vista de su performance, implica considerar que las instrucciones suministradas por los expertos son susceptible de cambios en su aplicación, realidad que la burocracia desconoce y pretende reducir como un absurdo. Por el contrario, muchas veces lo que está en juego en las ambigüedades de las instrucciones es el carácter inmanente y creadora de la acción.

En efecto, en el contexto actual es necesario reconocer como tabú ${ }^{1}$ la creencia, y también la acción burocrática acorde con ella, de que el vínculo entre la enseñanza y el aprendizaje es no problemático y puede resolverse a través del diseño de instrucciones por parte de expertos, reduciendo con ello al maestro de aula a un mero transmisor. Igualmente perjudicial es el supuesto de que la formación de los docentes en instrucciones mecanizadas resolverá lo que solamente puede ser afrontado in situ. En este sentido la repetición creadora propicia la novedad de lo singular devenido en acontecimiento, o sea, no solo considerando las particularidades tanto de las personalidades individuales como de los grupos y el contexto amplio, mediato e inmediato en que se encuentran los alumnos y el docente, sino más importante aún, atendiendo a lo nuevo ínsito en la verdad de los acontecimientos. Esta perspectiva conduce a considerar lo nuevo que surge en la educación, particularmente a la lección de que cualquier instrucción, por mucho que sea elaborada por expertos, se encuentra siempre agujerada por la situación en que irá a aplicarse. Esta sencilla máxima tan sabida y repetida de las más diversas maneras (p. e., Brockbank y McGill, 2002; Carr y Kemmis, 1988; Korthagen y Kessels, 1999; Shön, 1998; Stenhouse, 1987, entre varios otros) subyace en el nodo de la crítica y lo político como acto sustractivo, es decir, no objetivable, y nominable solo por sus consecuencias y en retrospectiva. Es en este punto en el que el término de acontecimiento de Badiou sirve para evitar caer, primero, en la anécdota fácil y cortoplacista de análisis de las tareas cotidianas y, segundo, en el vicio del estéril historicismo romántico, el cual se pierde en la explicación mediante la elucidación de "coyunturas" que, al enfocarse a los parámetros de la realidad establecida y sus opciones, limita sus análisis a lo posible. En contraste, el acto del corte en Lacan, como el de la invención política en Badiou, se caracterizan por afrontar lo imposible como afrontable. En esto consiste la locura de la sustracción, que hace referencia al carácter eterno de las verdades que no pecan pero incomodan. No es gratuito también que la noción de repetición vaya en contra del historicismo al enfatizar el constante recomienzo de afrontar lo imposible, en el intento tras intento manifestado en el síntoma.

De aquí que el reto sea, por tanto, el acto de la repetición creadora como torsión de la rutina burocrática en la enseñanza-aprendizaje. Ello, por muy compleja que pretenda presentarse y representarse, pues mientras no se reconozcan los vicios burocráticos que le afectan, especialmente los derivados de la división del trabajo entre expertos y ejecutores, no se podrá hablar de justicia en el sentido de igualdad de cuerpos con ideas, ya que uno de sus principales objetivos es la disciplina y la obediencia ciega a las

\footnotetext{
${ }^{1}$ Es decir, como algo inaceptable que debería reprobar la sociedad.
} 
instrucciones expertas. Contra la noción de la moral como un conjunto de ideales a los cuales se debe de adaptar la realidad, en años recientes ha tomado fuerza la visión alternativa de que lo importante es lo real contenido en las situaciones en donde se ejerce la búsqueda de la justicia como un ejercicio político (Badiou, 2007a). No se trata de una filosofía ni de una intervención política más. Tampoco es una consecuencia menor el que se propongan transformaciones de tamaña radicalidad. Para quienes se adscriben al reconocimiento de que las singularidades son presentables pero no representables, existe la posibilidad de lo nuevo no por lo nuevo mismo, como lo han solido hacer los modernistas en el campo del arte, sino de lo nuevo auténtico presentado como múltiple con variadas ramificaciones. Pero mientras tales nuevos acontecimientos surgen, corresponde a los militantes de la educación ejercer de sujetos fieles a los acontecimientos transformadores, mientras que a los intelectuales toca registrar a posteriori las consecuencias de los actos y acontecimientos transformadores.

En esta perspectiva, se da por descontada la vía de perseguir ideales esencialistas para, en cambio, hacer énfasis en otro tipo de disciplina no idealista, sino materialista: la disciplina de la participación en principios incondicionales como lo es la justicia percibida in situ, de la experiencia de la igualdad de los cuerpos con ideas. Así, no existe una justicia, ni siquiera justicias ideales, sino justicias en ejercicio dilucidables mediante el análisis de situaciones. El rechazo a los esencialismos de los ideales, lejos de significar la renuncia a cualquier orientación para la acción, reinstala en el corazón de la subjetividad la prioridad de los principios. A diferencia de los ideales, los principios, en vez de ser postulados a priori (como por ejemplo las tablas de Moisés), son siempre en situación y se caracterizan por exigir incondicionalidad además de no ser negociables. Los principios son fácilmente reconocibles cuando en el interior de acontecimientos estalla la luz interior que todos llevamos dentro, y nos hace capaces de participar en la eternidad contenida en las verdades concebidas como apenas posibles de decir, y las cuales "no pecan pero incomodan". Este tipo de verdades son rara vez analizadas a fondo, lo cual las convierte en un objeto de indagación sui generis aún insuficientemente explorado en sus amplias implicaciones, pues vivimos en un tiempo aristotélico (Badiou, 2002).

La defensa de la justicia como acción, específicamente como la defensa de cuerpos con ideas, se enfrenta a formidables dificultades dada la radicalidad de sus planteamientos, de entre los cuales uno de los más emblemáticos es la lucha por la desigualdad económica. La flagrancia de la violación del principio de la igualdad de los cuerpos con ideas en el terreno económico es en la actualidad más evidente que nunca, lo cual puede constatarse en la negociabilidad a la cual a diario es sometida como la más natural de las acciones. Ello pese a que, de acuerdo a la concepción de la justicia como acción, debería de ser un principio defendido de manera incondicional. Así como el anterior, podrían citarse numerosos ejemplos de perversión de la política, manifestada en la omnipresencia de las leyes y normas, y como la otra cara de la moneda, la invisibilidad de principios subjetivos universales e incondicionales.

En el presente artículo se desarrolla, en primer lugar, el análisis del fenómeno de la instalación del modelo fordtaylorista, como raíz a partir de la cual la rutinización de las tareas en el trabajo se constituyó como el eje principal de las concepciones esencialistas y doctrinarias de la moral, donde los ideales, que son planteados como estando "allí fuera", a manera de objetos supuestamente "objetivos", son impuestos a la realidad, de modo que se da inicio a la perenne pero inútil tarea de perseguirlos adaptando a ellos la realidad. Acorde con esta concepción de la moral como doctrina, los maestros de educación básica 
han padecido por varias décadas las imposiciones de una doctrina moral conformada por una excesiva normatividad, en la pretensión de sus superiores por estandarizar y controlar mejor su trabajo.

En un segundo momento se analiza la filosofía de la canallada inscrita en el núcleo de las doctrinas morales bajo la figura psíquica de lo que Jacques Lacan llamó el Gran Otro, cuya compleja operación como significante unario, no estando exenta de funcionar en el plano político, dada su rareza, oscila entre servir como recurso para la conjuración de temores y ser objeto de burla.

Posteriormente se alude a la concepción de Badiou de la justicia como la defensa de los cuerpos con ideas, la cual lejos de constituir una nueva canallada, alude a la libertad de elección de participación en principios y la consiguiente disciplina necesaria para sostenerse en ellos y, por ende, poder permanecer en la justicia.

El conjunto de reflexiones desarrolladas permite arribar a la conclusión de que las doctrinas morales, al pretender imponer ideales a la realidad, pervierten la calidad del esfuerzo ético de la búsqueda de justicia, mientras que por su parte las propuestas que se concentran en el análisis de situaciones como la sostenida por Badiou enfatizan la libertad ínsita en el carácter de apuesta de decisión, pensamiento y acción que exige posicionarse ante las verdades de los acontecimientos, ya sea como un sujeto fiel, reaccionario u obscuro. Este primero reconoce el tránsito de la imposibilidad hacia la posibilidad de lo nuevo auténtico, mientras que el segundo no ve nada nuevo bajo el sol al considerar en sus referencias exclusivamente las simples repeticiones del pasado, y el tercero simplemente niega que algo nuevo sucede. La decisión sobre lo que es un acontecimiento es subjetiva y atraviesa por lo que aquí propongo denominar cuasipolítica. Solo a posteriori se pueden dilucidar las consecuencias de dicha decisión. En particular, la propuesta de Badiou, más allá de las dificultades de comprensión de su ontología y demás formalismos, proporciona las armas para afrontar efectivamente la urgente tarea de lo real de las situaciones de justicia.

\section{La moral doctrinaria como ideología del trabajo autoritario y de repetición muerta}

Uno de los ideales máximos de la Ilustración es la educación. Originada en el siglo XVIII en ruptura con la fe teológica, desde entonces la educación secular persigue la mejora de los individuos y la sociedad mediante el uso de la razón. Específicamente, el legado de la Revolución Francesa hace más de doscientos años fue que los hombres podían gobernarse a sí mismos mediante la razón y la ley, y ya no por un rey con delegación divina. Para ello el supuesto ha sido que, con el desarrollo de las ciencias naturales y sociales en sus aplicaciones tecnológicas, se lograrían crear mejores condiciones de vida, incluyendo la realización de los ideales de justicia, libertad e igualdad.

Sin embargo, tales pretensiones se han dado durante más de dos siglos, en un contexto de expansión del capital y de los Estados nación en los diferentes países del mundo, lo cual no hubiera sido posible de no haberse impuesto la violencia del reclutamiento mediante la presión derivada del desempleo, así como una disciplina de tipo militar tanto en las fábricas como en las oficinas burocráticas del Estado. A través de la historia el autoritarismo subyacente a la organización del trabajo, cuyo objetivo es obtener 
dividendos mediante el sometimiento y la violencia, se ha disfrazado de diversas formas, lo cual principalmente ha ocurrido bajo el pretexto de la división racional de las actividades laborales (Gorz, 1977).

El supuesto doctrinario en que se apoya dicho disfraz, es que el uso de la razón contribuiría a legitimar a la organización del trabajo, una razón ejercida en una repetición de tareas muerta, o sea, escasa o nulamente creadora, donde la razón efectivamente empleada ha sido casi siempre una razón estrictamente cognitiva y lógica, misma que paradójicamente acabaría por acentuar la irracionalidad (Adorno, 1990; Braverman, 1983; Habermas, 2009; Lukács, 1969). Cuando en la vida consciente las prácticas carecen de congruencia con las ideas a manera de sobrecargar de irracionalidad las tareas cotidianas, se presenta una amplia posibilidad de que fuerzas inconscientes irrumpan en forma de exigencias de justicia. Así, por ejemplo, la palabra japonesa karoshi, que significa 'muerte por exceso de trabajo', alude a la verdad inconsciente de que la eficiencia en el trabajo o el trabajo por el trabajo mismo no lo es todo. Es entonces cuando se evidencian los límites del autoritarismo y la repetición muerta en el trabajo. Por paradójico que parezca, tal fenómeno también se da en el trabajo docente, donde supuestamente la prioridad es el trabajo vivo con ideas.

Una doctrina es un conjunto de ideales e instrucciones opacas a la razón porque no se pueden cuestionar y se exige para su seguimiento de una fe ciega, propiciándose así la represión de sentimientos y razonamientos sensatos que está prohibido expresar. Además de las doctrinas que aluden a la técnica para disfrazar el autoritarismo, se encuentran las doctrinas que se apoyan en las normas, a manera de mutilar la conciencia (Adorno, 1993) o fragmentarla (Thompson, 1993). El autoritarismo detrás de la racionalización y la repetición muerta tuvo uno de sus máximas expresiones durante la primer mitad del siglo XX, cuando la estandarización en varios aspectos de la vida laboral comenzó a imponerse tanto en las fábricas como en las oficinas. Al inicio, dicha estandarización adquirió la forma del denominado taylorismo, consistente en dividir las tareas laborales en los fragmentos de ejecuciones lo más eficaces posibles en cuanto al tiempo y gasto de energía. Dividir el trabajo y producir bienes o servicios se convierten en sí mismos en fines, haciendo de la palabra progreso un ideal incuestionado. Tal situación continuaría durante la década de 1930 con la difusión del modelo fordista de producción. El taylorismo y el fordismo fueron los dos principales modelos cerrados de producción en masa con base en los cuales se lograría la expansión del capital en el siglo $\mathrm{XX}$. Muchos teóricos del trabajo atribuyen las altas tasas de sindicalización a las reacciones de defensa frente al autoritarismo inherente a estos dos tipos de racionalización (p. e., Braverman, 1983; Burawoy, 1982). En el aspecto humano las más importantes consecuencias del taylorismo y el fordismo son:

- La limitación cognitiva que implica trabajar solo un fragmento del conjunto del proceso productivo, lo cual incapacita para intervenir, opinar o colaborar en el trabajo de los colegas (Gorz, 1977).

- La rígida obediencia de instrucciones de trabajo fomenta el desentendimiento del trabajador por responsabilizarse de los imprevistos, pues bajo este enfoque la culpa siempre se le puede atribuir a los expertos que diseñaron dichas instrucciones. 
- Desde el momento en que el saber lo proporcionan los expertos, se desincentivan los esfuerzos por ir más allá del conocimiento especializado en que, si acaso, los maestros se forman.

- La fragmentación del trabajo plasmada en un manual de procedimientos, un programa escolar o una antología no es creación propia y no invita a la creación de diseños propios, lo cual fomenta la apatía en el trabajo.

- La estandarización de las actividades laborales conduce a una homogeneización tanto de los docentes como del alumnado, que tienden a deshumanizarlos al limitarlos a tareas repetitivas, apegadas a un programa de trabajo aplicado de manera rígida.

En efecto, trabajar jornadas enteras o más realizando tareas repetitivas, reproduciendo a diario las recetas que los expertos elaboran, convierte el trabajo no solo en fatigoso y aburrido, sino en una actividad cercana a lo animal por la ausencia de ideas, si no es que muerto porque prohíbe la creatividad y lo nuevo. Aunque la repetición en sí misma no es algo necesariamente malo, se vuelve algo especialmente siniestro y perverso cuando indica un estancamiento que se reproduce cuando se realiza en automático, pues en tal caso nos encontramos ante el fenómeno del ejercicio de la memoria que desabastece de símbolos a la realidad, como afirma Lacan refiriéndose al fenómeno de la repetición en los modelos: "lo grave es más bien la deficiencia simbólica" (Lacan, 2010, p. 139). La catástrofe de la repetición también se manifiesta en el fracaso de Kierkegaard en su enamoramiento con Regina, al "proceder por la repetición a la creación de una forma nueva de su antigua relación” (Adam, 2005, p. 69).

En particular, el trabajo docente no escapa de la organización del trabajo fordtaylorista (González-Lara, Serrano-Camarena y Romero-Durán, 2014), especialmente cuando predomina la concepción bancaria de la educación como un proceso en el cual el docente deposita contenidos en la mente del educando (Freire, 1972). En efecto, una de los máximos equívocos en la educación es confundir la ciencia y la técnica con la aplicación de reglas como si fueran recetas. Con la aplicación del modelo fordtaylorista a la educación, el docente deviene en mero transmisor de conocimiento, sometido de manera programada a las órdenes que se transmiten desde las altas esferas burocráticas. El distanciamiento entre el conocimiento de los docentes y sus fundamentos científicos confirma la lamentable condición de dependencia con respecto a la figura del Gran Otro, señalada por Lacan como lugar del supuesto sujeto saber que se despliega como el Otro poseedor del saber absoluto. Lacan describe la dependencia con respecto al Otro como una atribución de fuerzas: "el Otro no es un sujeto, es un lugar al cual uno se esfuerza dice Aristóteles- por transferir el saber del sujeto” (Lacan, 1961, p. 20).

Desde la expansión de la industrialización hacia la segunda mitad del siglo pasado, la normatividad no ha dejado de estar muy presente en el mundo de los maestros de educación básica en muchos países del mundo. Los lemas, instrucciones, proyectos, planes y programas abundan mucho más que los documentos científicos, que son supuestamente los que deberían de servir como principal fundamento de su trabajo cotidiano. Ir más allá de la enseñanza mecanizada de instrucciones exige trascender la repetición del significante del docente como transmisor neutral de contenidos. En este sentido, la fundamentación científica y no solo filosófica del sujeto aún requiere de amplios desarrollos. Mientras tanto, las ciencias sociales más próximas a la reflexión de 
la práctica en lo futuro irán asimilando en nuevas e inéditas teorizaciones la necesidad del fenómeno de la sustracción en todo acto auténtico. Existe ya una amplia bibliografía en torno a esta corriente de pensamiento a la cual se le suele denominar filosofía posfundacional $^{2}$, pero que sin duda afecta a las ciencias sociales en general.

Trascender la visión del docente como transmisor implica deshacerse del fardo de controles burocráticos que pesan sobre su trabajo, a través de una reflexión que no se reduzca a la simple acumulación de reflexiones regidas por una aceptación de la realidad tal cual, sino más importante aún, se requieren reflexiones dialéctico materialistas capaces de efectuar rupturas y saltos, así como de tolerar irrupciones inesperadas de lo real inconsciente, donde lo simbólico se transforma. En los desarrollos pedagógicos recientes, la llamada "reflexión sobre la práctica", "docencia reflexiva" o "microenseñanza", constituye una aproximación al preconsciente, pero muchas veces las sugerencias de dichas disciplinas resultan insuficientes ante la necesidad de tocar lo real a través del significante capaz de resonar en el registro de lo simbólico (Olivo, 2011, p. 126).

A partir de lo anterior tenemos entonces que la necesidad de superación de la educación doctrinaria se da en dos planos; en el de la cognición lógica y en el de lo simbólico. En el plano de la cognición lógica, impera como medio de legitimación del poder la anteriormente señalada racionalidad limitada conducente a la irracionalidad. En cuanto al plano de lo simbólico, proliferan en el magisterio la figura de la ceremonia y la evocación solemne de las reglamentaciones. En la actualidad ambas resultan ser tan eficaces, incluso al punto de legitimar efectivamente mediante la fe, las acciones de los expertos aterrizando los procedimientos que recomiendan. Sin embargo, en contraposición a ello, el salto hacia lo imposible de la ausencia de la burocracia en la educación podría inventarse. Tal es la apuesta de pensamiento manifestada al enunciar la verdad en un acto de "cuasipolítica", la cual como se podrá advertir en los apartados que siguen, constituye el paso previo a la torsión de la realidad establecida como infranqueable.

\section{Crítica a la filosofía de la canallada}

La ideología no solo trabaja confundiendo lo real con la realidad, o propiciando la diversión a través de una vagancia entre signos y símbolos distanciados del contacto con lo real. El objetivo nodal de la ideología es, antes que nada, la dominación. Hay ideología en la medida en que el ejercicio de la dominación permanece oculto. Esto no significa que la necesidad sea, mediante una crítica de la ideología, trasparentar por completo y en sus detalles la dominación que unos ejercen sobre otros o a las estructuras que la posibilitan. Ello no es posible considerando que la figura del Otro siempre está presente aunque algunas veces parezca que no lo está. Es decir, la figura del Gran Otro fluctúa en diferentes momentos desde una presencia intensa hasta una aparente ausencia.

En la actualidad la discusión filosófica contemporánea se encuentra intensamente atravesada por dos corrientes de pensamiento mutuamente excluyentes. En una posición se halla la tradición de filósofos que ha imperado durante varios siglos, caracterizada por

\footnotetext{
2 Por ejemplo, véase el libro de Marchart (2009), donde se hace una amplia revisión de los autores más destacados que han escrito sobre la filosofía posfundacional.
} 
basar el conjunto de sus reflexiones en alguna idea central, como por ejemplo el bien (Platón), la libertad moral (Kant), el espíritu (Hegel), la vida (Nietzsche), el elemento místico (Wittgenstein), la especie humana (Adorno) o cualquier otra. En la segunda posición destacan varios autores que, haciendo eco de la ontología del impasse de las matemáticas -que desde hace un siglo comenzó a derribar la disposición parmenídea del ser como Uno-, enfatizan el vacío subyacente a cualquier idea que se pretenda postular como central para la elaboración de un sistema de pensamiento. La postulación del vacío como centro de las reflexiones exige detenerse a observar la situación que da lugar a las apuestas de pensamiento, sea que estas se presenten bajo la forma de un Uno o de lo múltiple, donde "lo uno no es" (Badiou, 2007b, p. 33).

De esta manera, los singulares que llegan a aparecer como rarezas inexplicables, sobre todo en forma de acontecimientos inesperados, son más pronto que tarde en una operación artificial convertidos en objetos unitarios perfectamente explicables y hasta clasificados desde la actividad política, jurídica y científica. Más específicamente, lo sensato es el reconocimiento de lo Uno como una operación artificial con su propia historia, mientras lo múltiple es el nombre del ser demostrable plenamente solo mediante la ontología de las matemáticas mas, sin embargo, con amplios efectos en el mundo del aparecer; o sea, el mundo tal y como se presenta a las percepciones cotidianas. Aunque el estudio de la falsedad de lo Uno tiene sus antecedentes en el Parménides de Platón, el cual consiste en demostrar la perforación de cualquier ser o discurso a manera de no concluir, más recientemente experimenta un poderoso relanzamiento con Lacan, quien planteó al significante del sujeto barrado o la falta en el sujeto, como el motor del deseo.

A fines de la década de 1950, Lacan advirtió que en el análisis de la falta existe una dosis de morbidez: "En efecto, no cabe duda de que lo abordamos, en su punto máximo, bajo este aspecto mórbido" (Lacan, 2013a, p. 10), donde el analista y la histérica comparten varias características en común. El caso más conocido es el de Aimée, paciente suya con quien entabló múltiples momentos de transferencia (Allouch, 2008). Pese a ello, insistió en la vía de torturarse con las reflexiones sobre la falta y los significantes que reverberan en sus efectos. No es gratuito, por ende, que sus categorías diagnósticas se concentraran más en las alteraciones (específicamente, la neurosis, la psicosis y la perversión) que en una determinada concepción de salud mental. "De hecho las categorías de la psicología popular en última instancia no son mejores ni peores que las que promulga la ciencia médica, ya que ambas tienen un abordaje síndrome-por-síndrome, síntoma-por-síntoma” (Fink, 1997, p. 150).

De cualquier manera, puede considerarse que en Lacan la histeria como modo de aproximación del analista para lograr la cura es un estado transitorio que se abandona una vez que se logra el pase. Sobre este punto, Badiou efectúa una torsión de 180 grados al renunciar a la morbidez de la reflexión sobre la falta, optando en cambio por la positividad de la multiplicidad genérica en los ámbitos del amor, el arte, la política y la ciencia. Uno de sus compañeros de batallas, Jacques Rancière, argumenta que la justicia es evanescente y aparece tanto como desaparece a momentos: "Él piensa que sólo hay momentos de justicia, la igualdad llega en un momento y luego desaparece inmediatamente" (Badiou, 2007a, p. 29). Estando parcialmente de acuerdo con Rancière, en su conferencia "Justicia, filosofía y literatura", Badiou reconoce la dificultad de hablar de la justicia. De aquí su afirmación de que "la justicia es oscura; la injusticia, por el contrario, es clara” (2007a, p. 19). Cuando alguien resulta agraviado sale a relucir la 
conciencia de la ausencia de la injusticia. Sin embargo, Badiou no se conforma con la definición negativa de la justicia como la ausencia de injusticia. Más importante aún, se opone tajantemente a la concepción aristotélica de justicia como los puntos medios entre opuestos a los que todos deberíamos de avocarnos. Detrás de dicha concepción, resuena un conservadurismo que durante más de dos mil años ha permanecido escasamente cuestionado, como afirma Bauman refiriéndose a tan larga permanencia de la ética aristotélica, esta no ha resistido durante tanto tiempo

porque todas las formas conocidas de comunión humana se hayan enfrentado al desafío y hayan cumplido efectivamente con las condiciones que ha señalado Aristóteles como atemporales, sino más bien porque a lo largo de la historia de la humanidad estas reflexiones no han dejado de atormentar, fastidiar y dar trabajo a la imaginación humana; de modo que continuaron impidiendo que cualquier forma de comunión en particular se fijara como límite de las posibilidades humanas. (Bauman, 2004, p. 72)

El status conservador de la política y la moral aristotélicas se evidencia en especial en el enciclopedismo que le caracteriza, al enfatizar la elaboración de cuadros descriptivos que sirven de "protocolos de legitimación" (Badiou, 2001, p. 99). En palabras más sencillas, su concepción de la ética como la búsqueda del punto medio tiende a promover la adaptación en lugar del cambio social. Otro aspecto aún más interesante del conservadurismo de Aristóteles lo ubicaría Lacan con la observación audaz de que detrás del establecimiento de un sentido hay una decisión. De aquí la razón por la cual "el sentido no puede ser sino equívoco, y esto se llama au-sentido" (Badiou y Cassin, 2010, p. 24). Tanto el au-sentido como el inconsciente son cosas que irrumpen inesperadamente más allá de las normas, para introducir en el lenguaje la influencia decisiva del deslizamiento de significantes a través de la metáfora y la metonimia.

En el trabajo del docente devenido en rutina y doctrinario, por un lado se encuentra el nivel del significado, donde se presentan, en un punto u otro del discurso hablado, "una imagen, un objeto, un sentimiento, un grito, un llamado. Es un continuo, mientras que por debajo, el significante está ahí como la pura cadena del discurso, sucesión de palabras, donde nada es aislable" (Lacan, 2013b, p. 373).

Veamos a continuación cómo el significante, elaborado como unidad (pero no aislable), se relaciona con la ética a través de la alusión de Dios. Como advertencia y nota aclaratoria, conviene señalar que la alusión de Lacan a escenas bíblicas se encuentra despojada de cualquier misticismo; por el contrario, en el mencionado seminario está construyendo el matema del point de caption.

El temor de Dios no es un significante que no rueda por todos lados. Fue necesario alguien que lo inventase y propusiese a los hombres, como remedio a un mundo de terrores múltiples, tener miedo a un ser que, después de todo, no puede ejercer sus malos tratos más que por los males que están ahí, múltiplemente presentes, en la vida humana. Reemplazar los temores innumerables por el temor de un ser único que no tiene otro remedio para manifestar su potencia salvo por lo que es temido tras esos innumerables temores, es fuerte" (Lacan, 2013b, p. 381).

Proyectar e incorporar fuerzas (miedos, deseos, sentimientos, etc.) en alguna persona, sea imaginada o recordada de lo vivido en la vida consciente pasada, es parte de un proceso psíquico que, en cuanto es clarificado en su función de la relación con el inconsciente, "la autonomía de la figura psíquica se disuelve" (Tacey, 2010, p. 33). O 
puesto en otros términos, ha dejado de vivir cuando la existencia "recorre su propia transparencia" (Badiou, 2002, p. 14). Lo anterior sucede en el marco más amplio de la relación con el Otro (con mayúscula), fenómeno que también puede suceder con el otro (con minúscula). En el psicoanálisis lacaniano, el (O)otro puede advenir en una figura psíquica que recolecta e incorpora lo malo, lo bueno, lo futuro, el género, etc., que el deseo indica. Sin embargo, rescatando la anterior cita de Lacan, más allá de la apariencia con la cual se presenta, lo que importa es la función de poder que la figura psíquica ejerce como un objeto-unidad, es decir, con el revestimiento de lo Uno, siendo que lo uno es resultado de la cerradura arbitraria de una cuenta (Lacan, 2012; Žižek, 2006; Žižek, 2015).

En la demostración del carácter arbitrario de la cuenta por Uno, Miller recurre a la paradoja de Russell originada en las observaciones que este le hizo a Frege ante el intento de este último por reducir las matemáticas a la lógica. Es decir, que las verdades de la matemática son deducibles de las verdades de la lógica (Miller, 2008, p. 22). Lo arbitrario de la cuenta por uno también se evidenciaría tres décadas después en la elaboración del teorema de incompletud por parte de Gödel, donde se demuestra la imposibilidad de sistematizar por completo las matemáticas (Nagel y Newmam, 1981).

Resulta significativo que a un número se le defina como la expresión de una cantidad con relación a su unidad. La cuestión comienza con el uno. Primero Lacan y después Badiou, ambos siguiendo en esto al Parménides de Platón, cada cual consideraría a lo Uno como falso. La cuenta por uno, sostienen, es producto de una operación arbitraria. Lo que cuenta como uno para alguien es porque ya se efectuó una operación de cerradura que define cierta cosa como una unidad. Aun cuando se trate de un conjunto de cosas contadas, por ejemplo, veintitrés cosas, y se les considere como un conjunto, se trata de una operación que tuvo su propia historia, su propio modo de justificarse y, por lo tanto, una operación histórica en la que ha existido la decisión de que el conjunto de veintitrés cosas exista. Cuando tratamos con números enteros, la primera pregunta ontológica obligada es ¿cómo surge el uno? Así, la existencia del uno plantea la primera cuestión de la diferencia entre uno y cero como una distinción entre lo que no existe y lo que existe. ${ }^{3}$

La justicia, al igual que los valores y los derechos humanos, no puede ser un objeto unitario ni mucho menos una cosa clarificable por completo en los momentos y situaciones donde existe un margen para la existencia de posturas contrarias plausibles. Este argumento podría prestarse a ser calificado como místico o posmoderno por la apertura o tolerancia que otorga a lo inexplicable. La superficialidad de tal juicio puede advertirse en que confunde saber con conocimiento. Un instinto, por ejemplo, es un saber aunque no podamos decir exactamente qué significa, pero funciona para el mantenimiento de la vida. Mucho del saber que funciona es preconsciente. Afirmar, por ejemplo, "que la nada pueda tener propiedades es esencial para la noción general de estructura" (Milner, 1996, p. 105). De esta manera, la idea de la estructura como efecto de la nada que representa la falta constituye un primer paso hacia el conocimiento de un deseo que, en primera instancia, se presenta como relativamente desconocido.

Así, la creencia obsesiva en la fuerza de lo Uno, cualquiera que sea la apariencia con la cual se presente (el Estado, Dios, una persona cercana o un desconocido, un objeto, etc.), puede dar lugar a un compulsión que pone en juego el amo absoluto, lo que Lacan llama

\footnotetext{
${ }^{3}$ Para más sobre la arbitrariedad de la operación de cerradura del Uno, puede consultarse Lacan (2012, pp. 123-163), así como Badiou (2002, pp. 11-36; 2007a, pp. 33-41) y Miller (2009, pp. 51-64; 2011, pp. 25-72).
} 
el Gran Otro, dando lugar con ello al vicio de la repetición (Masotta, 2011). Este argumento, lejos de abonar a la tibieza frente a la necesidad de justicia, o bien a su relajación, tiende por el contrario a ofrecer algunos lineamientos para fortalecerla, al considerar su carácter necesariamente abierto pero, sobre todo, alejado de ideales moralinos, utilitarismos cortos de miras o dogmas que suponen la verdad como algo conceptualmente diáfano y por tanto susceptible de someterse a manipulaciones.

Los derechos humanos o la justicia no son esencias en sí mismas consistentes. Ni mucho menos esencias fácilmente transmisibles mediante simples interacciones sociales o impartición de doctrinas. En su último libro, El fin de las sociedades, Alain Touraine alude de la siguiente manera a esta rara exterioridad de los valores:

Son los valores culturales mismos los que sustituyen a las normas sociales
institucionalizadas. Por lo general dichos valores se oponen directa y firmemente a
la lógica del lucro y del poder. Estos valores o principios no son sociales; se sitúan
por encima de las instituciones e incluso de las leyes. Podemos calificarlos de
morales, pero, en nuestra civilización, el sentido de esta palabra está cargado de
normas sociales y, en particular, de reglas de derecho. Prefiero para ello calificarlos
de éticos a fin de recalcar que proceden del exterior de la organización social, que su
contenido es universal y, por tanto, priva sobre las instituciones. (Touraine, 2016,
p. 14)

Para una comprensión no doctrinaria de los valores, es necesario saber en qué consiste dicha exterioridad. De esta manera, se estará evitando postular alguna entidad trascendente, como Dios, la ley, el Estado, los expertos, etc., cada uno de los cuales puede fungir en un momento determinado el papel del amo en cuanto se apropia del saber del esclavo (Lacan, 2013c, p. 38). Se podría considerar que la esfera exterior de donde provienen los valores culturales es la moral. Sin embargo, Touraine se niega a emplear la palabra moral por la intensa propaganda ideológica que han hecho de la misma los nuevos predicadores del derecho. Y aunque acierta en preferir la palabra ética por su cercanía con las cuestiones prácticas, dicha palabra tampoco se ha encontrado exenta de la contaminación ideológica de un supuesto retorno al hombre auténtico y sus derechos (Badiou, 2004, p. 30).

La omnipresencia actual de epistemologías que enfatizan las estructuras y no las excepcionalidades vuelve particularmente difícil la tarea de cuestionar la concepción de la justicia como una esencia. De igual magnitud se presenta el reto de pensar la justicia fuera de la noción acostumbrada de norma como el criterio para la restauración de la normalidad, donde se considera como imperativo adaptar la realidad a la norma en abstracto, en vez de analizar la situación en que determinada norma se actualiza. Tal es el caso por ejemplo de "Los ocho rasgos de la normalidad mínima", que en años recientes la Secretaría de Educación Pública planteó como la consigna a seguir por los docentes de educación básica en las escuelas:

Todas las escuelas deben brindar el servicio educativo todos los días establecidos en el calendario escolar, para ello las autoridades educativas locales y municipales deberán asegurar que las escuelas cuenten con el personal completo de la estructura ocupacional correspondiente, desde el inicio hasta la conclusión del ciclo escolar y evitar que se tenga personal por arriba de la estructura autorizada;

Todos los grupos deben disponer de maestros la totalidad de los días del ciclo escolar, por lo que las autoridades educativas locales y municipales deberán garantizar que la sustitución de personal que se requiera en la escuela, dentro del ciclo escolar, se realice en tiempo y forma; 
Todos los maestros deben iniciar puntualmente sus actividades;

Todos los alumnos deben asistir puntualmente a todas las clases;

Todos los materiales para el estudio deben estar a disposición de cada uno de los estudiantes y se usarán sistemáticamente;

Todo el tiempo escolar debe ocuparse fundamentalmente en actividades de aprendizaje;

Las actividades que propone el docente deben lograr que todos los alumnos estén involucrados en el trabajo de clase;

Todos los alumnos deben consolidar, conforme a su ritmo de aprendizaje, su dominio de la lectura, la escritura y las matemáticas, de acuerdo con su grado educativo. (Secretaría de Gobernación, 2014, p. 23)

Tales rasgos se concentran en los estándares medios deseables. Su conservadurismo se evidencia desde el momento en que no dicen nada acerca de los parámetros que es posible rebasar en su límite superior de los criterios señalados como, por ejemplo, por mencionar solo uno de entre los numerosos posibles, el trabajo autónomo con el maestro ausente. La defensa de la ética que enfatiza la inscripción de la letra escrita se presta a ser entendida como el sostenimiento de una idealidad proveniente de una instancia suprema a la que hay que obedecer sin cuestionarla porque nos han dicho que es conveniente y creamos en ella. En consecuencia, para proponer una ética no sujeta a esencialismos se hace necesario, e incluso casi inevitable, aludir un poco a la epistemología: los valores, antes que ser creencias, son representaciones. Cosas que, aunque se plantean como existiendo fuera de nosotros, no sabemos que ya forman parte de nosotros en el sentido de que nuestras percepciones intervienen en la manera en que interpretamos los objetos mismos "que están allí afuera".

Ahora bien, la representación del mundo como externo se ha convertido en al menos durante los últimos cinco siglos en nuestra rejilla epistemológica por antonomasia. Hace más de mil años los miembros de una tribu o un pueblo del medioevo no se podían concebir separados de su grupo, pues sus representaciones se encontraban regidas por las lógicas de conexión del grupo en su conjunto y no por las relaciones de los individuos consigo mismos y con el grupo. El destierro de Romeo lejos de Julieta y de Verona, o bien el destierro de Edipo de la ciudad de Tebas, significaba la muerte en vida. El individuo simbólica y cognitivamente fundido en su comunidad es la versión social de lo que en relación con la naturaleza Piaget llamó antropomorfismo, término con el cual se alude a la atribución de vida consciente a los objetos que no la tienen (Halbawchs, 1977).

La noción de individuo inaugurada formalmente en Occidente por Descartes es relativamente reciente (Ruelle, 2010). Durante los siglos XVI y XVII, conforme los individuos comenzaron a percibirse separados del grupo al que pertenecen, de manera paralela comenzó a concebirse un mundo como externo, es decir, fuera de nuestras existencias individuales e incluso fuera de nuestra existencia como individuos en grupo. La representación del mundo externo incluye cualquier cosa de la que podamos elaborar una unidad aislada. Así, la ética es una de las cosas que de acuerdo a nuestra rejilla epistemológica contemporánea pertenecen al mundo externo. Es entonces cuando aparece el planteamiento de que podemos apropiarnos de las cosas supuestamente objetivas llamadas ética, moral o justicia, relacionándonos de determinada manera con los demás. De este modo se instala la percepción de que es posible apropiarnos de dichas abstracciones consideradas como esenciales como lo hacemos con muchos otros "objetos externos". 
De lo anterior se desprende que la ética implica la representación de algo externo que ha solido tener el nombre de "el bien". Muchos, religiosos, humanistas, utilitaristas, estoicos, etc., dirán que "el bien" es un ideal deseable de alcanzar, pero antes que un bien es una representación formada desde nuestras peculiares formaciones. Es decir, una unidad externa cuya identidad es planteada como consistente por la necesidad de estabilizarla cognitiva y simbólicamente, a manera de que sirva como orientación para manejarnos en el mundo. ¿Cuántas entidades no ha creído el hombre que irían a darle la solución definitiva a su existencia errante? ¿Cuántos ideales morales se han pensado como la solución que finalmente vendría a arreglarlo todo? ¿Cuántas veces se ha experimentado el tropiezo cuando creía haberse arribado a una orientación verdadera? Innumerables. Tantísimas que sorprende la tenacidad con la cual el ser humano, una y otra vez, se plantea de manera incesante representaciones del bien. Es debido a esta inextinguible persistencia de la necesidad de representarse el bien que no puede plantearse, por insensata, la idea de que la ética es un invento superficial que se debería abandonar para ubicarnos, como diría Nietzsche, "más allá del bien y del mal".

Sin duda cualquier determinada representación de la ética, así como de la justicia, se dirige a satisfacer la necesidad existencial y emocional de creer que algo mejor adviene. El problema es creer, de manera predominante, que el advenimiento de algo mejor será en automático. Es decir, sin desplegar esfuerzos por realizar la representación del ideal de bien que se tiene. Tales esfuerzos han de estar arraigados en una primera instancia, en términos del tipo de lo que aquí denomino cuasipolítica: la potencialidad del acto de un enunciado de atravesar lo imposible con una verdad. Con el término de cuasipolítica, se designa al acto de educar en la elaboración de enunciados de verdad del tipo de los que no pecan pero incomodan, definición que encaja congruentemente con la concepción de Badiou de la educación como el acto de hacer los arreglos necesarios para la manifestación de verdades que no son opiniones, y que significan la posibilidad de algo nuevo (Heyer, 2010). Con la moral como doctrina, aparte de que se nos proporciona una definición esencialista del bien, la justicia, los valores, la moral, etc., se nos ahorra el esfuerzo de buscar por nuestros propios esfuerzos los criterios para aplicarlos. He aquí la diferencia crucial entre doctrina y educación.

En la doctrina se comete la canallada de difundir como propaganda la creencia de que lo elaborado por las instancias trascendentes para nosotros debe ser inamovible: determinados esfuerzos deben emplearse de determinadas maneras y enfocarse sobre determinadas áreas de nuestras vidas, mientras otros se proscriben por prohibidos o inconcebibles. En cambio, en la educación se pretende ofrecer en libertad y responsabilidad los medios para decidir y actuar en lo conveniente para todos. Asimismo, tales medios y fines, en lugar de ser fijos, se encuentran abiertos a un permanente cuestionamiento, ello no porque se pretenda ajustar la realidad a una abstracción ideal, sino sencillamente para permanecer en la acción justa. Lo anterior significa que en la educación se mantiene viva la llama del deseo y el esfuerzo por una vida mejor, que será constantemente buscada a través de la razón, el espíritu, las emociones y, en suma, cualquier medio que facilite experimentar que la acción debida continúa. 


\section{La ética de la igualdad de los cuerpos con ideas y la enunciación de verdades en la cuasipolítica}

Para Alain Badiou se impone la imperiosa necesidad de concebir la justicia como el lugar de la potencia en que las virtudes de la sabiduría, el valor y la sobriedad se activan, a manera de contribuir a la existencia de una determinada secuencia política (Badiou, 2009, p. 106; 2013, p. 174). En este marco cabría concebir que, no obstante que las verdades son enunciados apenas dichos, se pueden pensar otro tipo de enunciados previos a ellos y que pueden apuntar a incentivar la reflexión sobre lo imposible, como lo es la cuasipolítica de oponerse enunciativamente a los vicios de la burocracia en la educación, proclamando la igualdad de los cuerpos con ideas. Esta fórmula es comprensible para el habitante de lo que Badiou llama "una extensión genérica” (2007b, p. 556), para quien los vicios burocráticos derivados de la división del trabajo entre expertos y ejecutores en la enseñanza, tienen una existencia real y desea su desaparición. Por poner un ejemplo de entre varios otros posibles en el mundo: ante la proximidad de los tiempos electorales en México, la aplicación de exámenes de evaluación estandarizados a los docentes de educación básica fue suspendida extraoficialmente desde el mes de julio de 2016, pues al menos ya no se aplican de manera tan extensiva como antes, de modo que los docentes han obtenido una victoria subjetiva silenciosa. En tal contexto, la burocracia tiende a ser pensada de modo diferente en sus coacciones. Lo antes concebido como imposible, es decir, la aplicación de los exámenes de permanencia, ahora es pensada como removible: la no aplicación de los exámenes. Los enunciados en torno a esta verdad potencian lo antes concebido como imposible, o sea, ingresan a la cuasipolítica en forma de pensar potenciando lo imposible.

Este planteamiento va más lejos y se encuentra en oposición radical a la mediocre concepción negativa de la justicia, la cual en la actualidad pregona una obsesiva reclamación de los derechos como defensa de la sobrevivencia propia de los pobres, así como de otros tipos de víctimas (p. e., los niños o mujeres maltratados, los prisioneros torturados, los alumnos acosados, etc.) que han sido degradadas a la condición de animales hasta el punto del conformismo con la vida como simple sobrevivencia. De manera acostumbrada, el derecho prodigado de manera amplia en nuestras sociedades contemporáneas es reducido a no ser molestado en la persona y los bienes que se conservan. Se exhorta así constantemente a rezar el significante de la mortalidad, en la apática confirmación de la anónima existencia pasajera:

$$
\begin{array}{r}
\text { Con energía haz tu larga y pesada tarea } \\
\text { en la que la vida te quiso llamar } \\
\text { y sufre y muere luego, como yo, sin hablar. } \\
\text { (Vigny, citado en Badiou, 2013, p. 156) }
\end{array}
$$

Resulta poco menos que sorprendente que el soldado desconocido o el veterano estadounidense de la guerra de Vietman se hayan instalado entre los principales emblemas de las guerras del siglo XX: la paradoja del héroe devenido en objeto a, la cual no causa algún gusto imaginar ocupar su lugar y, no obstante, tiene estatuas en su memoria. Confirmación de que su trascendencia ha devenido en superficial, en casi una 
burla. Como suelen decir los conformistas funcionalistas: "Ser hombre es aprender, saber cuál es tu rol en esta sociedad y cumplirlo" (Junger y Quested, 2014).4

La difusión de la mediocridad de la ética aristotélica se extiende a un gran número de figuras operantes en varias esferas bajo la apariencia de excesos normalizados y aceptables como, por ejemplo, el joven sin causa, los escándalos de las estrellas del espectáculo, los políticos corruptos, etc. que por ahora no viene al caso revisar aquí. En particular interesa destacar los excesos involucrados en una polaridad que, en medio y en contraste con muchas otras que supuestamente tenemos la libertad de "pensar", permanece no obstante incuestionada en su núcleo: la divisoria entre pobres y ricos.

Más allá de la discusión de si tal desigualdad ha logrado ser instalada o no en el sentido común como algo natural, se encuentran los excesos a que ambos dan lugar. A saber, los excesos propios del amo y del esclavo (Kojève, 2013, p. 70). La riqueza económica conforma las condiciones para el desempeño del papel del amo en tanto quien la goza se encuentra en la paradójica situación de que está excluido de la posibilidad de enfrentarse a lo real a través del trabajo. De aquí las locuras nihilistas de cualquier tipo a que da lugar el ocio. La pobreza económica, por el contrario, significa exceso de trabajo para mantenerse a nivel de la sobrevivencia física. Kojève plantea que el esclavo tiene una superioridad simbólica y moral sobre el amo (porque aparte de su contacto más realista con el mundo mantiene latente el deseo de liberación, mientras el amo se ve limitado a conservar su poder sobre el esclavo y a mantener una vida ociosa), mas su liberación es solo una posibilidad, ya que el verdadero peligro es que la relación entre el esclavo y el amo se reproduzca y mantenga ad infinitum en el circulo vicioso de los extremos que tornan infelices a ambos. Más básicamente, el ejemplo del amo y el esclavo muestra que la infelicidad no proviene de los excesos en sí mismos, sino del sesgo contenido en promover unos excesos como buenos siendo malos, y ocultando o condenando otros que pueden ser buenos. ¿No es acaso la noción cantoriana secular de infinito, despojada de cualquier aurea religiosa, un exceso que puede ser bueno porque muestra la posibilidad de participar de lo eterno?

Por otro lado, rara vez se asume seriamente la pregunta de por qué la ética aristotélica, la dominante hoy en día y mediante la cual se dice defender el punto medio de equilibrio entre excesos, no se utiliza para condenar los vicios relacionados con la riqueza y la pobreza. El asunto va más lejos que la ética como la defensa del punto medio: lo que se halla en juego es la reducción de la existencia a la vida animal en la idea de su "respeto". Con tal tipo de ética, lo excelso ínsito en la dignidad de la singularidad y la participación en lo eterno y lo genérico es desechado.

Evidentemente, de la lectura atenta de los escritos de Badiou se desprende que la participación en lo eterno y lo genérico no equivale a la megalomanía de insertarse en los grandes acontecimientos históricos mundiales, ni tampoco a los más grandes de acuerdo con cualquier criterio. Aquí lo que importa no es la amplitud de la secuencia política, sino la ubicación de la existencia con relación a la verdad sea cual sea la dimensión en que esta se presente, ya sea en el de la vida cotidiana, en los sueños, en el

4 Autores del documental The Last Patrol, que aborda la triste situación de los veteranos de guerra de última generación en Estados Unidos. A manera de terapia un grupo de ellos reflexionan sobre su difícil adaptación a la vida normal. Al final, llega la supuesta cura con el enunciado: "Lo que ocurre con la guerra es que finalmente puedes entender bien que eres insignificante y que todo se da aleatoriamente. Pero también obtienes algo increíblemente valioso a cambio. Entiendes lo hermoso que es estar vivo”. ¿No confirma este dicho la condición de animal mortal en que la ética dominante de hoy nos ha colocado? 
círculo de personas cercanas o con desconocidos. Con la verdad sucede algo parecido a la parodia de la llegada de un contradiós que Badiou plasma en "La República de Platón":

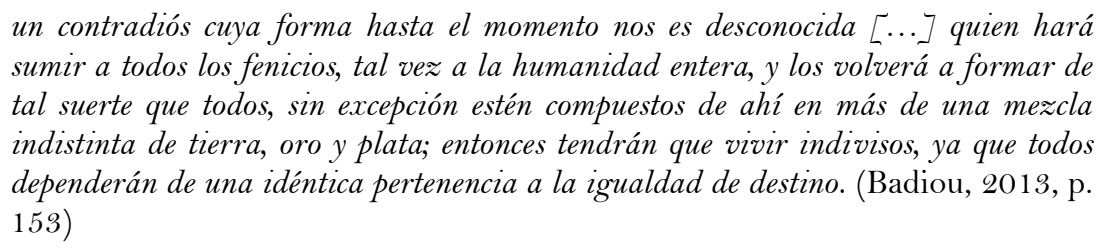

Aunque apenas posible de decir, la verdad es subjetiva. Sin embargo, igual para todos en cuanto que todos tenemos la luz interior de saber qué es el bien más allá de cualquier norma escrita o definición en forma de enunciado. Durante el terremoto en Ciudad de México en 1985, una gran cantidad de gente salió a las calles a las labores de rescate. Entre ellas se encontraba el famoso tenor Plácido Domingo, a quien días después, cuando ante la urgencia gubernamental de reinstalar la normalidad las retro excavadoras se llevaban con prisas a los basureros de Texcoco los cuerpos fragmentados a trozos, un reportero le preguntó si no temía que el polvo y el cascajo le arruinaran la voz, a lo cual el cantante respondió: "Lo que me importa es que los cuerpos se recaten con dignidad” (Poniatowska, 2005).

Los ejemplos de participación en la eternidad son numerosos, aunque en el sentido común rara vez se les asocia a la justicia, al ser relegados y reducidos a la anécdota. Sin embargo, su poder movilizador es indudable. En la Segunda Guerra Mundial, los nazis soltaron los perros a trece niños polacos que habían sobrevivido al frío gracias al calor proporcionado por una pila de cuerpos de sus compañeros muertos en el interior del vagón de un tren. Después de haber sido estos devorados, los nazis persiguieron a los dos últimos niños que quedaban, quienes echaron a correr pero, al poco tiempo, uno de estos últimos desaceleró y extendió su mano al otro, para inmediatamente ambos caer ante los golpes de las porras, pero con las manos unidas. Žižek alude al acto de participación en la eternidad ínsita en este relato, en la forma de las dos manos unidas de los niños burlándose de la prepotencia nazi. Como la sonrisa del gato en "Alicia en el País de las Maravillas”, su imagen se congeló, lográndose instalar en la psique como un significante unario (Žižek, 2014, p. 80). He aquí la fuerza evidente de una verdad eterna. Por supuesto, en el campo de la educación y específicamente de la ruptura con el performance de la repetición muerta del trabajo docente, sobrarían los ejemplos de aparición de verdades eternas.

La forma de la justicia es entonces la de la lucha, y por lo tanto concierne directamente a la política real en oposición a los simulacros de política, los cuales se encuentran sometidos al cálculo de la ganancia y la armonización de los intereses. En contraste, el raro acto del ejercicio justo de la política encuentra su piedra angular en el ejercicio incondicional de los principios, que son anteriores a las leyes, a manera de participar de manera inmanente del templo de lo divino en la interioridad subjetiva. En la parodia que hace Badiou (2013) del diálogo entre Sócrates y Glaucón, este último se opone a la idea de controlar la riqueza económica de los gobernantes, cuyas actividades, a diferencia de otras profesiones, exigen del conocimiento y afrontamiento de situaciones.

Ante la idea de controlar la riqueza a los gobernantes, de modo que no posean palacios, rebaños, automóviles, jarros de lujo, mujeres arrobadoras, perfumes o joyas, Glaucón protesta diciendo que si no se les otorga buenos incentivos a los gobernantes se les hundiría en la miseria y no harían bien su trabajo, pues lo que se debe de dar como 
incentivos es el derecho a gozar por sus esfuerzos. A lo que Sócrates hábilmente responde que ello significaría corromperlos, al ofrecerles bienes y goces que terminarían por desviarlos del seguimiento de los principios interiores que supuestamente poseen y que deben de seguir, sobre todo el de la lucha incondicional por el bien de todos. De otra forma, lo que estarán haciendo será cualquier cosa menos política real. Con respecto a los gobernantes dice el Sócrates parodiado:

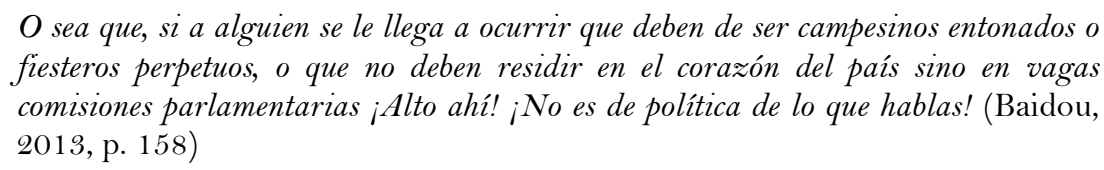

Aun cuando el bien se reconozca en momentos especiales como la luz que todos llevamos dentro, y a la cual todos somos capaces de debernos de manera incondicional con la dignidad de la idea, el solo acto de reconocerla resulta insuficiente, pues sigue la tarea aún más dura de disciplinarse con los compromisos de las consecuencias de estar en la justicia. Es aquí donde la justicia se convierte en algo mucho más cercano a la practicidad de la ética que a la idealidad de la moral, intuición a la que se aproxima Touraine sin reconocer el carácter de decisión y compromiso que defiende Badiou contra cualquier historicismo romántico. Una vez que el acontecimiento y el compromiso del sujeto fiel han acaecido, sigue la apuesta en los axiomas, los cuales trabajan de manera muy diferente a la programática propia del pensamiento occidental. Los primeros dos axiomas son la igualdad de la capacidad de participación en la verdad y la igualdad de los cuerpos con ideas. No se puede saber de antemano la forma, el nombre ni el enunciado concretos que la justicia adquirirá, pues corresponde al campo de lo singular el despliegue de lo que específicamente el esfuerzo por lo justo ha de enfrentar.

Es una practicidad que, sin embargo, se encuentra lejos de manipulaciones y de los intereses del mundo de los bienes materiales. El ejercicio de la disciplina que de manera incondicional requiere el estado activo de estar en la justicia implica el despliegue de una axiomática política desde el momento en que está sometida a secuencias políticas singulares. Por lo tanto, la concepción de la justicia que sostiene Badiou, al asignarse a un sujeto caracterizado por la rareza de lo político (toda vez que exige un compromiso decidido, incondicional y subjetivamente asumido por la igualdad y valor universal de los cuerpos con ideas, práctica considerablemente escasa pero necesaria), se mantiene casi siempre invisible en su capacidad para modificar radicalmente las coordenadas de determinadas situaciones (Badiou, 2009, p. 106), no importando la pequeñez o amplitud de su espacio temporalidad, sino su conexión con verdades apenas posibles de ser dichas, pero con resonancias decisivas para quienes deciden y asumen el compromiso de fidelidad para con las mismas.

Entre los obstáculos o posibles caminos de desvío de la justicia entendida como defensa comprometida y disciplinada de los cuerpos iguales con ideas, se encuentra las anteriormente señaladas figuras del Gran Otro y del otro. El Gran Otro puede incluso tomar la forma de un objeto a cuando deviene en otro (con minúscula) y adquiere las características de un resto parcial, no especulativo y pulsional (Le Gaufey, 2013, p. 19); un resto desilusionante que, como un desecho, deviene pequeño, despreciable o menos que nada y, sin embargo, no se puede renunciar a gozarlo. Como afirma Žižek: "nunca puedes liberarte de la mancha del goce, el gesto mismo de renunciar al goce produce invariablemente un plus de gozar" (1994, p. 38). 
Aunque Le Gaufey asevera que el objeto a no se puede definir porque sencillamente no es un concepto, los esfuerzos por aproximarse a dicha noción no cesan. Así, por ejemplo, existen en Internet algunas aproximaciones aceptables, como la siguiente de Correa, que concuerda con lo expuesto por Lacan (Lacan, citado por Le Gaufey, 2013, p. 30), en sus seminarios del 13 y el 20 de mayo de 1959:

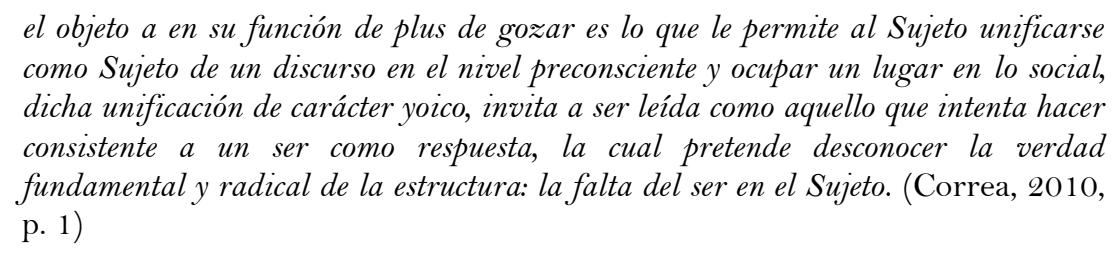
como Sujeto de un discurso en el nivel preconsciente y ocupar un lugar en lo social, dicha unificación de carácter yoico, invita a ser leída como aquello que intenta hacer consistente a un ser como respuesta, la cual pretende desconocer la verdad fundamental y radical de la estructura: la falta del ser en el Sujeto. (Correa, 2010, p. 1)

Existen abundantes ejemplos de las maneras en que funciona el objeto a, de entre los cuales la figura del rey desnudo es una de las más conocidas; a pesar de que el rey ha sido humillado, sigue habiendo cierta solidaridad con él. En el famoso anime japonés Dead Note, el protagonista Light Yagami, después de sentirse el amo del mundo, deviene al final en la verdad del simple asesino que es: se convierte en el objeto a; el desecho que la idea del bien moral colectivo prefiere arrojar a la basura del olvido y, sin embargo, de manera inconsciente no deja de existir en los espectadores una complicidad relativamente no confesada de solidaridad con el sujeto caído.

Hay momentos también en que el Gran Otro, en lugar de derivar en el goce perverso de solidaridad con el otro con minúscula, adquiere la forma de la cortés ignorancia que mantiene el orden social estable como, por ejemplo, cuando sabedores de la corrupción de un funcionario que inaugura una obra pública, los asistentes a la ceremonia guardan un cortés pero cómplice silencio. O cuando el educado joven Francés Léaud es acusado por falta de tacto cuando al entrar a un baño sin avisar y ver que alguien se estaba duchando, se disculpa diciendo iPardon Madame!, ya que hubiera sido mejor que antes de cerrar rápidamente la puerta hubiera tenido el tacto de decir ¡Pardon Monsieur! Žižek también refiere el ejemplo de la cortés ignorancia en la experiencia de una mujer que golpeaban ante varios vecinos y nadie llamó a la policía creyendo que otro vecino lo haría (Žižek, 2015, p. 105).

En la medida en que el (O)otro se presenta ante el sujeto como el objeto a con la cual pretende ocultar la falta o, en tanto el sujeto barrado (representado por Lacan como \$) procure disimular su incompletud, estará evitando el encuentro con lo real. En este punto se hace necesario abrir un breve paréntesis para distinguir entre lo real y la realidad. Esta última sirve de base para la cognición y las acciones estables que permiten enfrenar el mundo de todos los días. En cambio, lo real es lo incognoscible, la zona o la cosa que no se puede saber qué es sino solo la fuente de todo efecto imprevisible. Pretender que la esfera de la moral se limita a la realidad de los usos, costumbres, normas, creencias y valores que guían la conducta adecuada en sociedad conduce al error de suponer que es diáfana, que se puede conocer y explicar con claridad en todos sus recovecos. De ser así, no existieran en absoluto problemáticas morales, lo cual de otra manera equivale a recordar la concepción de Freud del afrontamiento de la cosa como habilitadora de la ética.

De acuerdo con lo anterior, cuanto más firme sea la creencia en un Otro (sea la Ley, Dios, un gobernante, etc.), como conjurador de la falta y los miedos relacionados con la misma, más se estará negando lo real. En este sentido bien se pudiera estar de acuerdo con Chesterton cuando señala que es "una postura razonable negar los adoquines de la 
calle; será dogma religioso negar su existencia” (citado por Žižek, 2015, p. 424). El problema de la advertencia de Chesterton estriba en que resulta iluso pretender permanecer siempre en lo real, considerando que no se puede evitar la postulación de una realidad, pues esta constituye la textura del mundo de la vida, misma que al garantizar la seguridad ontológica permite estabilizar la existencia. No obstante, el escepticismo tiende a mostrarse en nuestra contemporaneidad más favorable a la antiviolencia que los fanatismos. De aquí la razón por la cual superar la antifilosofía de Lacan, exige reconocer en el pensamiento lacaniano la fundamental oposición -realizada sin recurrir a algún metalenguaje-, a cualquier idea que funcione como piedra de toque de cualquier sistema de pensamiento engatusador, conducente a lo que Lacan denominó la canallada (Badiou, 2008, p. 78).

Los argumentos anteriores conducen a la lección de que hace falta un trabajo de disolución del Gran Otro y del otro con minúscula, para estar en condiciones de ejercer una ética genuina, pues les es propio enfrentarse a lo real de Das Ding, de la cosa, sin requerir el apoyo o referencia a un sujeto supuesto creer (Žižek, 2015, p. 135). En efecto, la entidad, cosa, persona o letra a la que le otorgamos la posesión del saber, de hecho no sabe sobre nosotros. En este sentido, la cura es posibilitada por la disolución de las apariencias de dicho saber:

Sería de veras muy peculiar que ese sujeto que se supone saber, de quien se supone que sabe algo sobre uno, y que, de hecho, nada sabe de eso, pueda considerarse liquidado en el momento en que, al final del análisis, empieza precisamente a saber algo, al menos sobre uno. (Lacan, 2013d, p. 275)

\section{Conclusiones}

A la luz de las reflexiones anteriores, se puede concluir que el performance central de los docentes en la idea de justicia es decidir si hacen algo o no contra la desigualdad entre diseñadores y ejecutores. La idea de repetición muerta, en contraste con la de repetición creadora, exige definirse como alguno de los tres tipos de sujetos: fiel, reaccionario u oscuro. Solo el primero se afirma en la inconsistencia. Si, por ejemplo, la verdad apenas dicha es que los vicios de la burocracia que conducen a la desigualdad deben de acabar, la aseveración de que ello es absurdo afirma el dos desigual promovido por la burocracia: los diseñadores y los ejecutores, mientras que la enunciación de su desaparición confirma la inconsistencia y las consecuencias de la misma en el caso en que la verdad advenga como un indiscernible en el vacío de una situación.

Por su parte, la mera enunciación de verdades no basta para provocar transformaciones a partir de singulares situacionalmente localizados. Así el término de "cuasipolítica" indica la potencialidad de un acto y un acontecimiento y, solo cuando el enunciado deviene en su materialidad en el mundo, se convierte en política en la acepción de la irrupción de la novedad capaz de transformar las coordenadas básicas de una situación. Uno de los peligros del término de cuasipolítica, es que se muestre como insuficiente al momento de convocar una nueva divisoria que rompe con los significantes establecidos. Sin embargo, en compensación, conlleva la ventaja de señalar la necesidad del debate acerca de la relación entre lo que tiene lugar previamente a la torsión y el surgimiento abrupto de esta, en el sentido de atreverse a preguntar de maneras más amplias e imaginativas dicha relación: ¿Cómo es que en la nueva situación el pasado adquiere un semblante de 
eternidad al tiempo de hacer venir a la existencia lo anteriormente inexistente? ¿Cómo lo antes concebido como imposible de moverse, en el momento en que se constituye un sujeto colectivo deviene en algo que efectivamente se mueve? Para emplear palabras de Bosteels (2010, p. 25), el acontecimiento " ¿no es una creación ex nihilo absoluta, sino una producción que comienza desde los bordes de un vacío”? Tal pregunta puede ser explorada y respondida desde las diferentes disciplinas de las ciencias sociales y no solamente desde la filosofía. Así, la idea de nuevas concepciones de las coerciones percibidas o de transformación de lo antes percibido como inamovible potencialmente abre una nueva atmósfera para pensar en contexto y desde la sociología la combinación de matema-arte requerida en el registro posterior que los intelectuales hacen de los acontecimientos disruptores, pues corresponde a los políticos militantes de cualquier figura ligar la rareza de la presentación a la representación de lo nuevo surgido en el acontecimiento.

La concepción de la justicia como acción de fidelidad incondicional al principio de la dignidad de los cuerpos con ideas implica luchar a contracorriente de las tendencias hoy dominantes de la ética y la política. Su diferencia principal con respecto a la doctrina de la ética aristotélica esencialista del punto medio reside en que, en lugar de pretender adaptar las situaciones a los ideales, se concentra en la posibilidad de instalación de los principios en el corazón de la subjetividad, en el momento de acontecimientos en los cuales se da la posibilidad de la participación de los seres existentes en verdades eternas.

Las concepciones de los filósofos posfundacionales sobre la nada y el ser, en este caso de Alain Badiou, que parte de la tesis de la nada positiva o multiplicidad pura, para después de ello plantear las verdades que apenas se pueden decir, o sea, indiscernibles, indecidibles e innombrables (Badiou, 2003, p. 171), no facilitan (además porque no se encuentra entre sus objetivos centrales) la difusión de la concepción de justicia que sostienen, ya que las verdades y principios que nacen del acontecimiento poseen su propia potencia incondicional. En especial, la noción de cuasipolítica como acto enunciativo de una verdad potencialmente capaz de atravesar lo imposible se propone aquí como la apuesta de un pensamiento para militantes fieles entre los docentes y ampliable a otras figuras políticas. En este tenor, la tarea del filósofo es servir de guardián pensador de los acontecimientos. Esto puede entenderse mejor señalando tres momentos en los que Badiou plantea la defensa de la justicia, a la cual aquí añadimos el término de cuasipolítica.

- Primeramente, la cuasipolítica puede concebirse y ser presentada como el acto enunciativo de una verdad sin raíz material para lograr transformación alguna, pero aún contenedora de potencialidades porque no peca pero incomoda (como lo es la verdad del vicio de la repetición muerta contenida en el fenómeno de la burocracia en la educación).

- Después, de manera aleatoria, como resultado de la proclamación de un enunciado de verdad en el campo de la cuasipolítica, puede darse el momento decisivo del estallido inesperado de un acontecimiento disruptor, del cual poco se puede saber, pero cuyos efectos pueden ser definitivos para la creación de nuevas y raras secuencias políticas. Aquí la nada, que funge como motor del acontecimiento, toma la forma de la ausencia capaz de causar efectos en el ser (Badiou, 2003, p. 103). Además, su presencia como real se puede demostrar con 
plenitud a través de la ontología de las matemáticas de los impasses (Badiou, 2007b, p. 13).

- En un tercer momento, la torsión de lo real en los acontecimientos abre la posibilidad de que las subjetividades que han tomado nota de los mismos en lo general asuman alguna de las tres figuras de sujeto: fiel, reactivo y oscuro (Badiou, 2008a, p. 65). En el sujeto fiel se asume el compromiso con la verdad eterna, fácilmente reconocible como un principio incondicional surgido desde el interior más íntimo de la subjetividad. En el sujeto de la negación, se prefiere creer que fijarse en el acontecimiento no es algo que valga la pena porque fue un engaño o una vana ilusión. Y para el sujeto oscuro el acontecimiento no es tal, sino otra cosa sobre la cual no vale la pena detenerse a pensar ni hacer algo simplemente porque no existe, y no puede hacerse nada frente a lo que no existe.

- El cuarto momento es el de la disciplina del sujeto por mantenerse fiel a las consecuencias derivadas de su compromiso con los principios asumidos a partir de su conexión con la verdad del acontecimiento. Tal disciplina exige trabajar y pensar por axiomas, que es muy diferente a la conocida tradición occidental de organizar la acción programáticamente (Hallward, 2003, p. 227). La continuidad de las secuencias políticas depende de las intervenciones en las cadenas de acciones que constituyen a los sujetos (Feltham y Clemens, 2003, p. $6)$.

A través de estos tres momentos, se puede advertir más claramente la tajante diferencia entre la concepción doctrinaria de la justicia y la concepción sostenida por Badiou. El momento de decisión y de apuesta sobre cómo posicionarse ante el acontecimiento es una situación en donde la filosofía de Badiou, lejos de imponer una guía para la acción, enfatiza las posibilidades de invención abiertas al infinito, comenzando por las invenciones aventuradas previas a los acontecimientos, como la que aquí se ha propuesto con el término de cuasipolítica. Por su parte, el pensamiento sobre la decisión de fidelidad a los acontecimientos de verdad solo puede ser formal, pues corresponde a los creadores de la política (pero también del arte, la ciencia y el amor), desde sus propias condiciones, asumir o no los principios y la disciplina de dicha fidelidad. De la capacidad del ser para asumir los infinitos ínsitos en las verdades de los acontecimientos depende la posibilidad del ejercicio de una nueva política y ética de la justicia. Tal es la principal diferencia con respecto a la moral como doctrina, que hoy por hoy nos mantiene maniatados en la noria del sermón repetitivo.

\section{Referencias}

Adam, R. (2005). Lacan y kierkegaard. Buenos Aires: Nueva Visión.

Adorno, T. (1990). Dialéctica negativa. Madrid: Taurus.

Adorno, T. (1993). Consignas. Buenos Aires: Amorrortu.

Allouch, J. (2008). Marguerite o la aimée de lacan. Buenos Aires: El Cuenco de Plata.

Apple, M. (2003). Introducción. En D. P. Liston y K. M. Zeichner, Formación del profesorado y condiciones sociales de la escolarización (pp. 11-16). Madrid: Morata.

Badiou, A. (2001). Breve tratado de ontología transitoria. Barcelona: Gedisa. 
Badiou, A. (2002). Tratado de ontología transitoria. Barcelona: Gedisa.

Badiou, A. (2003). Condiciones. Ciudad de México: Siglo XXI.

Badiou, A. (2004). La ética. Ensayo sobre la conciencia del mal. Ciudad de México: Herder.

Badiou, A. (2007a). Justicia, filosofía y literatura. Buenos Aires: Homo Sapiens.

Badiou, A. (2007b). El ser y el acontecimiento. Buenos Aires: Manantial.

Badiou, A. (2008a). El balcón del presente. Conferencias y entrevistas. Ciudad de México: Siglo XXI.

Badiou, A. (2008b). Lógica de los mundos. El ser y el acontecimiento 2. Buenos Aires: Manantial.

Badiou, A. (2009). Compendio de metapolítica. Buenos Aires: Prometeo Libros.

Badiou, A. (2013). La república de Platón. Ciudad de México: Fondo de Cultura Económica.

Badiou, A. y Cassin, B. (2010). No hay relación sexual. Buenos Aires: Amorrortu.

Bauman, Z. (2004). La sociedad sitiada. Ciudad de México: Fondo de Cultura Económica.

Bosteels, B. (2010). Lógicas del cambio: de la potencialidad a lo inexistente. En C. Gómez Camarena y A. Uzín Olleros (Comps.), Badiou fuera de sus límites (pp. 1-30). Buenos Aires: Imago Mundi.

Braverman, H. (1983). Trabajo y capital monopolista. La degradación del trabajo en el siglo XX. Ciudad de México: Nuestro Tiempo.

Brockbank, A. y McGill, I. (2002). Aprendizaje reflexivo en la educación superior. Madrid: Morata.

Burawoy, M. (1982). Manufacturing consent: changes in the labour process under monopoly capitalism. Chicago, IL: Chicago University.

Carr, W. y Kemmis, S. (1988). Teoría crítica de la enseñanza. La investigación acción en la formación del profesorado. Barcelona: Martínez Roca.

Correa, E. (2010). La identidad y la identificación: Laclau y Žižek. Revista Carta Psicoanalítica, 15, $1-24$,

Feltham, O. y Clemens, J. (2003). An introduction to Alain Badiou's philosophy. En A. Badiou, Infinite thought. Truth and the return to philosophy (pp. 1-38). Londres: Continumm.

Fink, B. (1997). Introducción clínica al psicoanálisis lacaniano. Buenos Aires: Gedisa.

Freire, P. (1972). Pedagogía del oprimido. Ciudad de México: Siglo XXI.

González-Lara, J. M., Serrano-Camarena, F. A. y Romero-Durán, E. E. (2014). Formación universitaria integral para el desarrollo. Revista de Educación y Desarrollo, 30, 25-32.

Gorz, A. (1977). Crítica de la división del trabajo. Barcelona: Laia.

Habermas, J. (2009). La lógica de las ciencias sociales. Madrid: Tecnos.

Halbawchs, F. (1977). Reflexiones sobre la causalidad física. En M. Bunge, F. Halbwachs, T. S. Kuhn, L. Rosenfeld y J. Piaget (Eds.), Teorías de la causalidad (pp. 25-46). Salamanca: Sígueme.

Hallward, P. (2003). Badiou. A subjet to truth. Minnesota, IL: University of Minnesota Press.

Heyer, K. (Ed.). (2010). Thinking education through Alain Badiou. Sussex: John Wiley \& Sons.

Kojève, A. (2013). Introducción a la lectura de Hegel. Madrid: Trotta.

Korthagen, F. y Kessels, J. (Eds.). (1999). Linking practice and theory. The pedagogy of realistic teacher education. Mahwah, NJ: Lawrence Erlbaum Associates. 
Lacan, J. (1961). L'identification. Séminaire 1961-1962, Leçon 1, 15 novembre 1961. París: Publication hors commerce Document interne à l'Association freudienne internationale et destiné à ses membres.

Lacan, J. (2010). El yo en la teoría de Freud y en la técnica psicoanalítica. Buenos Aires: Paidós.

Lacan, J. (2012). ...o peor. Buenos Aires: Paidós.

Lacan, J. (2013a). La ética del psicoanálisis. Buenos Aires: Paidós.

Lacan, J. (2013b). Las psicosis. Buenos Aires: Paidós.

Lacan, J. (2013c). El reverso del psicoanálisis. Buenos Aires: Paidós.

Lacan, J. (2013d). Los cuatro conceptos fundamentales del psicoanálisis. Buenos Aires: Paidós

Lukács, G. (1969). Historia y conciencia de clase. Estudios de dialéctica marxista. Ciudad de México: Grijalbo.

Marchart, O. (2009). El pensamiento político posfundacional. La diferencia política en Nancy, Lefort, Badiou y Laclau, Buenos Aires: Fondo de Cultura Económica.

Masotta, O. (2011). Ensayos lacanianos. Buenos Aires: Eterna Cadencia.

McLaren, P. (1995). La escuela como un performance ritual. Ciudad de México: Siglo XXI.

Miller, J. (2008). Matemas II. Buenos Aires: Manantial.

Miller, J. (2009). Conferencias porteñas. Tomo 1. Buenos Aires: Paidós.

Miller, J. (2011). Donc. La lógica de la cura. Buenos Aires: Paidós.

Milner, J. (1996). La obra clara. Lacan, la ciencia, la filosofía. Buenos Aires: Manantial.

Nagel, E. y Newmam, J. (1981). El teorema de Gödel. Ciudad de México: Consejo Nacional de Ciencia y Tecnología.

Olivo, M. (2011). ¿Hasta dónde saben los docentes? Estudio de caso: unidad o98 de la UPN. Ciudad de México: Universidad Pedagógica Nacional.

Poniatowska, E. (14 de septiembre de 2005). Nada, nadie. Las voces del temblor veinte años después. La Jornada. Recuperado de http://www.jornada.unam.mx/2005/09/14/index.php?section=cultura\&article=a07a1cul

Quested, N. y Junger, S. (Productores) y Junger S. (Director). (2014). The last patrol (Película) Estados Unidos: HBO

Ruelle, A. (2010). L'émergence de l'individu entre formes substantielles et droits essentiels. Bruselas: Facultad de Saint-Louis.

Schön, D. (1998). El profesional reflexivo: Cómo piensan los profesionales cuando actúan. Barcelona: Paidós.

México. (2014). Acuerdo número 717 por el que se emiten los lineamientos para formular los Programas de Gestión Escolar.

Stenhouse, L. (1987). La investigación como base de la enseñanza. Madrid: Morata.

Tacey, D. (2010). Cómo leer a Jung. Ciudad de México: Paidós.

Terrén, E. (1999). Educación y modernidad. Entre la utopía y la burocracia. Barcelona: Anthropos.

Thompson, J. (1993). Ideología y cultura moderna. Teoría crítica en la era de comunicación de masas. Ciudad de México: Universidad Autónoma Metropolitana Xochimilco.

Touraine, A. (2016). El fin de las sociedades. Ciudad de México: Fondo de Cultura Económica. 
Turner, V. (Comp.). (1987). The anthropology of performance. Nueva York: Paj Publications.

Žižek, S. (1994). ¡Goza tu síntoma! Jacques Lacan dentro y fuera de Hollywood. Buenos Aires: Nueva Visión.

Žižek, S. (2006). Porque no saben lo que hacen. El goce como un factor político. Buenos Aires: Paidós

Žižek, S. (2014). Acontecimiento. Ciudad de México: Sexto Piso.

Žižek, S. (2015). Menos que nada. Hegel y la sombra del materialismo dialéctico. Madrid: Akal.

\section{Breve CV del autor}

\section{Miguel Ángel Olivo Pérez}

Doctor en Ciencia Social con Especialidad en Sociología por El Colegio de México. Autor del libro Los niños vulnerables, publicado por editorial Gedisa en 2013, y del libro ¿Hasta dónde saben los docentes? El caso de la Unidad 098 de la UPN, editorial Horizontes, de la UPN, en 2011. Responsable del proyecto de investigación Vulnerabilidades educacionales a nivel preescolar, financiado por el Consejo Nacional de Ciencia y Tecnología (CONACYT) en 2012 y 2013. Miembro del Sistema Nacional de Investigadores, nivel 1. Miembros del Cuerpo Académico Sociología de la Educación Básica, del Programa del Desarrollo del Profesorado (PRODEP). Autor de más de 30 ponencias en congresos nacionales e internacionales, Premio Nacional de Investigación laboral en el año 2006. ORCID ID: O000-0002-4571-6972. Email: miguelangelolivo@hotmail.com 